\title{
Development of Intersection Management Strategy Due to Opening of Sumatra Toll Road
}

\author{
S Rahma ${ }^{1}$,R A E Putra ${ }^{1}$ \\ ${ }^{1}$ Civil Engineering Department, Institut Teknologi Sumatera, Lampung Selatan, Lampung
}

\begin{abstract}
The main role of a transportation network is providing optimum services for transportation network. Over the time, the population is increasing and the needs of reliable transportation network also increased. Transportation network consists of node and connector. According to the condition, the provision of reliable transportation network facilities should be able to optimize the node and the link. In the real condition, there's a gap between the existing transportation network conditions with the optimum transportation network conditions, as a result the existing transportation network is not able to serve the transportation movement that occurred. Based on this information, research entitled Development of Intersection Management Strategy Due to Opening of Sumatra Toll Road. The objective of this study are: a) Generating traffic flow through the Simpang Polsek Sukarame, Bandar Lampung. b) Evaluating the traffic composition through Simpang Polsek Sukarame, Bandar Lampung. c) Evaluating services intersection parameters needed in evaluating the intersection. d) Determining the intersection strategy of intersection due to the opening of the Sumatra Toll Road. The study is conducted by using Macroscopic Modeling approach using PTV Vissum application and microscopic evaluation using MKJI 1997. In the research, there are several types of data needed. These data are classified into primary and secondary data. Primary data required include: a) Traffic Counting Data, TC Data implemented at Simpang Polsek Sukarame. Traffic Counting data is used as a database for the validation of the transportation model. b) Road geometry data is taken at all connector of Simpang Polsek Sukarame. The Geometry consist of the road width and shoulder width. Geometry data is used for capacity calculation, delay, and saturation degree. From the results of transport modelling that will be evaluated the service level of the intersection based on the parameters of degree of saturation, delay, and speed of vehicles through the intersection. The Result of the model shows that The queue length increasing from $10.66 \mathrm{~m}$ to $16.64 \mathrm{~m}$ or increasing for around $60 \%$ and the average delay increasing from $7 \mathrm{~s}$ to $13.43 \mathrm{~s}$ or increasing around $95 \%$. It will be concluded that the addition of toll road traffic is affecting the intersection performance.
\end{abstract}

Keywords : Microscopic Model, Intersection Management, Toll Road.

\section{Introduction}

The development of a city always related to the increasing of transportation traffic as a derivate needs of people. In the term of engineering, increasing of transportation needs mean the increasing needs of transportation infrastructure. In the other side, transportation infrastructure facing another constrain. The constrain is land availability for those infrastructure. Referring to that condition, in the research of Development of Intersection Management Strategy Due to Opening of Sumatra Toll Road will develop several policy related to intersection management. The research located at Simpang Sukarame, Kota Bandar Lampung, Provinsi Lampung. The research process approached by microscopic transportation simulation using PTV Vissim. From this research will be evaluated the intersection condition and it will 
be conducted several policy related to Simpang Sukarame. At The other hand Do nothing policy show that the queue length and delay value is $13.14 \mathrm{~m}$ and $16.64 \mathrm{~s}$.

\section{Literature Review}

\subsection{Intersection}

The intersection is an inseparable part of the road network. In urban areas usually have many intersections, where the driver must decide to walk straight or turn and move the road to achieve one goal. In general there are 3 (three) types of intersections:

1) An level intersection,

2) Separating road lanes without ramp,

3) Interchange.

\subsection{MKJI 1997}

The Indonesian Road Capacity Manual (MKJI 1997) states that traffic performance measures include Level of Performance (LoP). LoP means a quantitative measure that describes the operational conditions of a traffic facility as assessed by the road builder. The performance measures of unsignalized intersections can be stated by:

- Capacity (C)

- Degree of saturation (DS)

- Delay (D)

- Queue opportunities (QP\%)

\subsection{Capacity}

MKJI (1997) defines that capacity is the maximum traffic flow that can be maintained in a part of the road under certain conditions stated in vehicle / hour or pcu / hour. The total capacity of an intersection can be expressed as a result of multiplication between the base capacity (Co) and the adjustment factors (F). The formula for intersection capacity according to MKJI 1997 is written as follows:

$$
\mathrm{C}=\mathrm{Co} \times \mathrm{FW} \times \mathrm{FM} \times \mathrm{FCS} \times \mathrm{FRSU} \times \mathrm{FLT} \times \mathrm{FRT} \times \mathrm{FMI}
$$

with:

$\mathrm{C}=$ Actual capacity (according to existing conditions)

$\mathrm{Co}=$ Basic Capacity

FW = Incoming width adjustment factor

$\mathrm{FM}=$ Factor adjustment of the main road median

FCS $=$ City size adjustment factor

FRSU $=$ Adjustment factor for the type of road environment, side obstacles and non-motorized vehicles.

FLT $=$ Factor adjustment ratio turn left

FRT $=$ right adjustment ratio factor

$\mathrm{FMI}=$ Adjustment factor for minor road current ratio

\subsection{Transportation Modelling}

The basic purpose of transportation planning is to estimate the number and location of transportation needs (the number of trips, both for public transport and private transport) in the future or in the year of planning for an effective and efficient transportation investment policy. To produce good transportation planning, a tool is needed or known as a model.

Traffic growth will be directly proportional to the addition of networks and infrastructure related to transportation. As for if it is studied globally, it will use macroscopic transportation modelling. The macroscopic model generally models the traffic flow that occurs in a large number of vehicles on a road. 
Along with the needs of transportation planning, there have been several models in the form of software or software that are used as a tool in the formulation of an analysis. One of the software used is PTV Visim, which is a transportation modelling program to analyse existing traffic conditions, forecasting that supports GIS or Geographic Information Systems data.

\section{Research Methodology}

\subsection{Research sites}

In this research, there is conducted a case study in Simpang Polsek Sukarame, Kecamatan Sukarame, Bandar Lampung. This Location is managed under authority of Depertement Of General Development Provinsi Lampung.

\subsection{Research Data Collection Method}

Research Data collection is proceeded by two approaches:

1. Primary data

Primary data is collected by traffic counting located at Simpang Sukarame for its approaches. Another primary data which is collected is the geometry of Simpang Sukarame approaches.

2. Secondary data

The secondary data which is collected is the potential movement from bakauheuni to lampung province to estimate calculation of total vehicle which is passing by simpang sukarame.

\subsection{Data Processing Analysis}

The method that used in this research is Microscopic Transport Modelling, which is developed by combining traffic counting data and network development plan using PTV Vissim Application. There are several scheme which is run using PTV Vissim: Do Nothing 2019, Road Widening 2019, Signalized Intersection 2019, Do Nothing 2024, Road Widening 2024, Signalized Intersection 2024, and flyover 2024. From those scheme, it will be conducted the evaluation of intersection performance for each scheme.

\subsection{Research Flow Chart}


ICOSITER 2018 Proceeding

Journal of Science and Applicative Technology

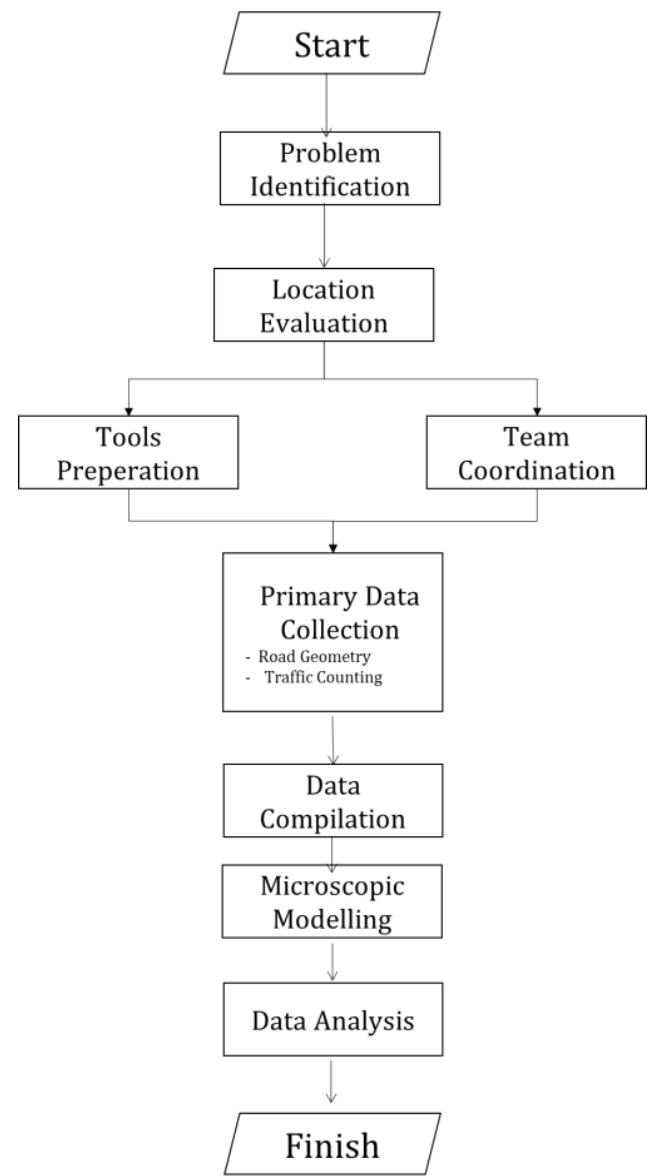

Figure 1 Flowchart of Research Methodology 


\section{Results and Discussion}

In this section will be showed the results and discussion of the research that has been carried out will be presented. The results of the study are the results of primary data with various planned schemes

\subsection{Primary Data Collection}

- Road Geometry

Each approach has its own characteristic which is showed at Figure 2.

\begin{tabular}{|c|c|c|c|c|}
\hline No & Approach & Type & Road (m) & Median (m) \\
\hline $\mathbf{1}$ & ITERA (U) & 2/2 UD & 5.9 & - \\
\hline $\mathbf{2}$ & KORPRI (S) & $4 / 2$ D & 6 & 4.6 \\
\hline $\mathbf{3}$ & Jl. P. Senopati (T) & 2/2 UD & 5.1 & - \\
\hline $\mathbf{4}$ & Jl. Airan Raya (B) & 2/2 UD & 5.1 & - \\
\hline
\end{tabular}

Figure 2. Road Geometri

\section{- Intersection Traffic}

From this intersection there are four approaches for the intersection. Each intersection movement classified into direction and vehicle class which is showed at figure 3.

\begin{tabular}{|c|c|c|c|c|c|c|c|c|c|}
\hline & \multicolumn{3}{|c|}{ LT } & \multicolumn{3}{|c|}{ RT } & \multicolumn{3}{c|}{ ST } \\
\hline Pendekat & MC & LV & HV & MC & LV & HV & MC & LV & HV \\
\hline ITERA (U) & 94 & 16 & 2 & 76 & 26 & 5 & 623 & 256 & 15 \\
\hline KORPRI (S) & 511 & 112 & 28 & 61 & 21 & 3 & 756 & 240 & 16 \\
\hline Jl. P. Senopati (T) & 78 & 12 & 1 & 178 & 21 & 5 & 343 & 21 & 5 \\
\hline Jl. Airan Raya (B) & 121 & 23 & 0 & 307 & 127 & 27 & 128 & 22 & 2 \\
\hline
\end{tabular}

Figure 3. Traffic Counting Data

The highest traffic movement is from ITERA and KORPRI Approach which motorcycle take a highest vehicle composition.

\subsection{Scheme Evaluation}

\section{Queue Length (m) dan Delay (detik)}

\section{口Queue Length Delay}

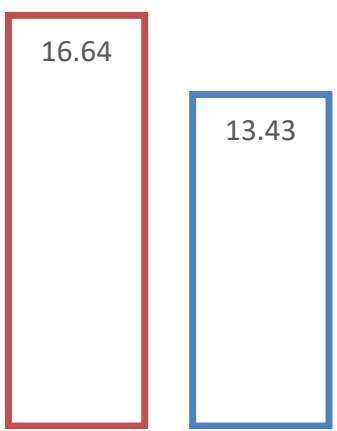


Figure 4. Comparison Basic Traffic and Toll Road Traffic

In this research there are conducted 4 scheme for the traffic policy. Those 4 scheme are do nothing, road widening, signalized intersection. First, Due to opening toll road there is an effect to the intersection $128 \mathrm{pcu} / \mathrm{h}$. At figure 4 there is showed the comparison of average queue length and delay for basic traffic movement and Traffic with JTLS traffic movement addition. The queue length increasing from 10.66 $\mathrm{m}$ to $16.64 \mathrm{~m}$ or increasing for around $60 \%$ and the average delay increasing from $7 \mathrm{~s}$ to $13.43 \mathrm{~s}$ or increasing around 95\%. It will be concluded that the addition of toll road traffic is affecting the intersection performance. If there's not any change, it will be problem for the intersection.

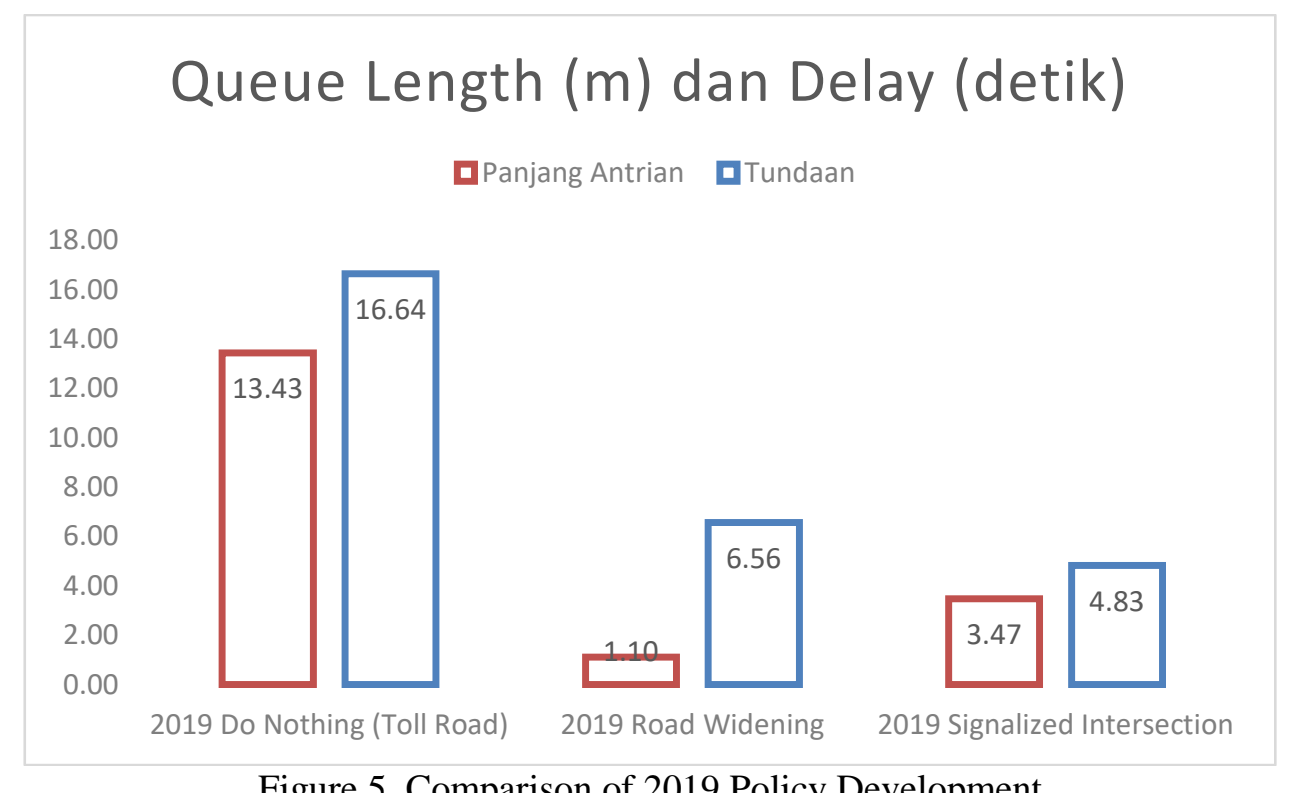

Figure 5. Comparison of 2019 Policy Development

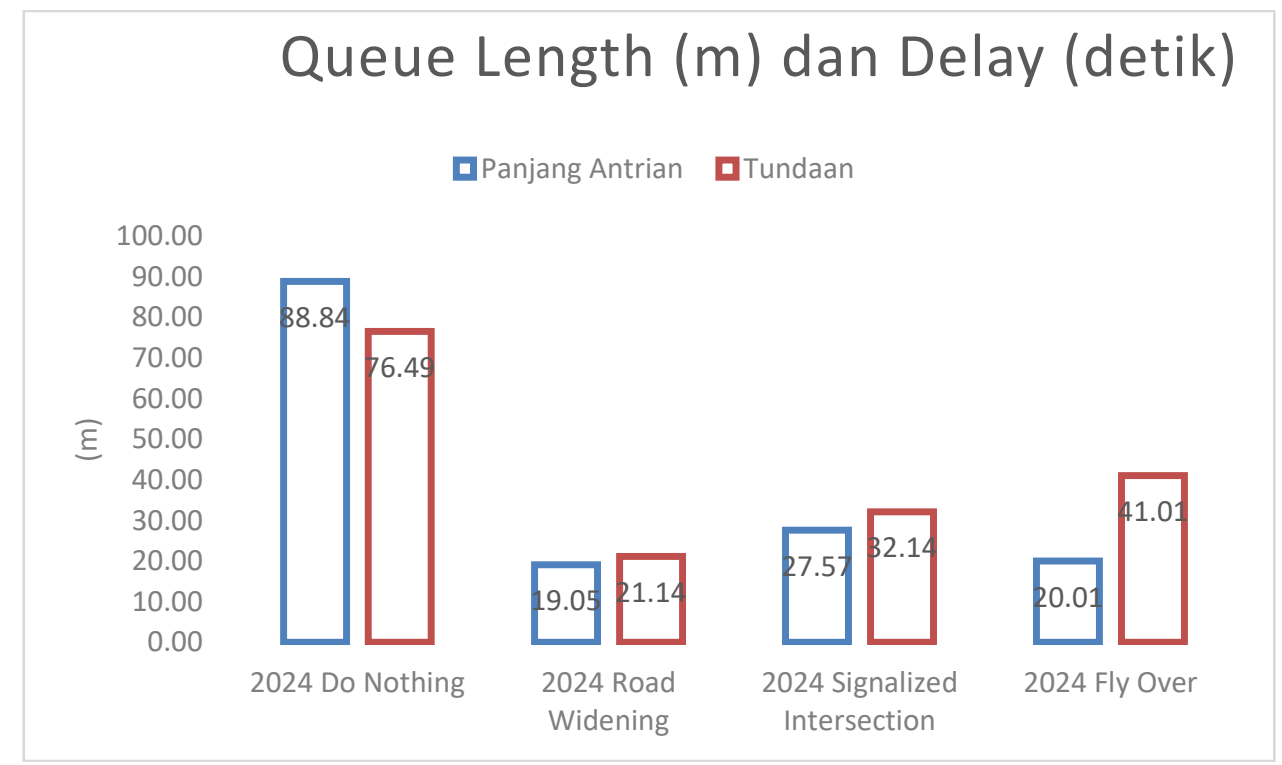

Figure 6. Comparison of 2024 Policy Development

In figure 5 there is showed the comparison of some policy that is developed. Do nothing policy show that the queue length and delay value is $13.14 \mathrm{~m}$ and $16.64 \mathrm{~s}$. This value is not big but it has potential to 
increase for the next years. The other policy which is conducted is road widening for ITERA approach and develop actual same size with korpri approach. Because of this policy the queue length and delay decreasing more than $100 \%$. The next policy which is developed is signalized intersection. From the data the characteristic of this intersection not fit enough for signalized intersection.

In figure 6. Also shows the comparison of 2024 policy development. Do nothing in 2024 increasing immensely from 2019. This is caused by the traffic growth for simpang sukarame. If we develop the road widening policy in 2024, the performance increase more than $100 \%$. Siganalized intersection not effecting the road condition because the road properties are not better than road widening. In 2024 there is added Fly Over option. If compare to road widening, the properties difference is not significant. It happen because the traffic condition is not big enough for the fly over.

\section{Conclusions}

In this research, there is showed that addition of JTTS traffic is affecting the transportation condition to $60 \%$. So it might be developed several option management policy in this intersection. For network performance indicator, road widening and fly over is two choices is fit for the policy development but if evaluated benefit and cost ratio, road widening will be better than flyover.

\section{References}

[1] Departemen Pekerjaan Umum, (1997). "Manual Kapasitas Jalan (MKJI)”, Departemen Pekerjaan Umum, Direktorat Jenderal Binamarga, Jakarta.

[2] Khisty. C.J dan Kent L.B, (2005). "Transportation Engineering”, An Introduction/Third Edition. Published by Pearson Education.

[3] PTV VISION, (2014). "PTV VISUM 17 - New Fitures at a glance", PTV AG, Karlsruhe, Germany.

[4] Tamin, Ofyar Z. 2010. Perencanaan dan Pemodelan Transportasi. Penerbit ITB Bandung. 